\title{
INTRODUCING INTERNET OF THINGS (IOT) FOR A COMMUNITY VILLAGE BASED ON INDUSTRIAL REVOLUTION 4.0
}

\author{
Sri Ratna Sulistiyanti ${ }^{{ }^{*}}$, F.X. Arinto Setyawan ${ }^{1}$, M. Komarudin ${ }^{1}$, Warsono ${ }^{2}$ \\ ${ }^{1}$ Department of Electrical Engineering, Universitas Lampung, Bandar Lampung, Indonesia \\ ${ }^{2}$ Department of Mathematics, Universitas Lampung, Bandar Lampung, Indonesia \\ *Corresponding Author: sriratnasulistiyanti@gmail.com
}

\begin{abstract}
A house is a gathering place for a family, where each family member has a different passion and busyness. If at any time a family member is traveling and wants to monitor and control conditions from a distance, an electronic device is used. One solution to determine the condition of home security at all times, an internet connection is needed by using the concept of the Internet of Things (IoT). IoT is a concept of using an internet network to transfer data or share information with certain applications. The IoT concept is one of the IR 4.0 based systems. In Indonesia, the system has not been widely implemented, especially for village areas. The purpose of this activity is to introduce the concept of IoT in a region as a system of monitoring and controlling homes. The method used is socialization and training of IoT-based smart home models. The system that is introduced is setting lights, monitoring gas (kitchen security), and monitoring using a camera. The results obtained were an increase in knowledge from $45.4 \%$ to $79 \%$, and increased skills from $33 \%$ to $63 \%$.
\end{abstract}

Keywords: IoT, Village, Industrial Revolution 4.0.

\section{INTRODUCTION}

Home is a place to live to meet daily needs. Along with the times, today many use electronic systems in homes or buildings. The technology used in general to monitor home security is only limited to the scope of the house so the homeowner does not know the condition of the house while traveling. So, when the owner of the house is traveling or not at home, the owner does not know the condition of the security of his house.

One solution to knowing the condition of home security at all times is that an internet connection is needed because the internet is always connected from all corners of the world using the concept of Internet of Things (IoT), the concept of using internet networks to transfer data or share information with certain applications (Pei, 2010). One of the services used in the IoT concept is Firebase. Firebase is a Google Cloud Service Provider (CSP) and Backend as a Service (BaaS) that allows users to store data and read data in real time (Moroney, 2017). The use of IoT in various fields has been widely developed in the world, but in fact, the concept of IoT is rarely applied in Indonesia.

In the era of the Industrial Revolution 4.0, the use of IoT will be even wider. It is a challenge for universities to socialize and provide training on simple IoT applications to the community, especially the village community. This needs to be done so that people can use IoT positively.

\section{LITERATURE REVIEW}

Security and home automation concept (Kodali, 2016) explain in Figure 1. Quad structure of smart home network could be seen in Figure 2. Nurfaif (2017) using the miniature smart home for implementation smart-home-system. The application of smart-home-system on the smartphone could be seen in Figure 3. The three types of smart-home system are used for socialization and training of IoT-based system.

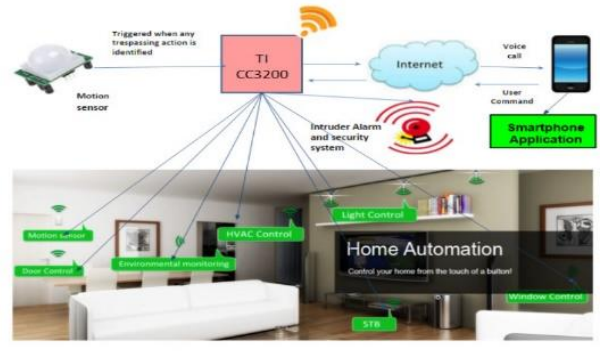

Figure 1. Security and Home Automation (Kodali, 2016) 


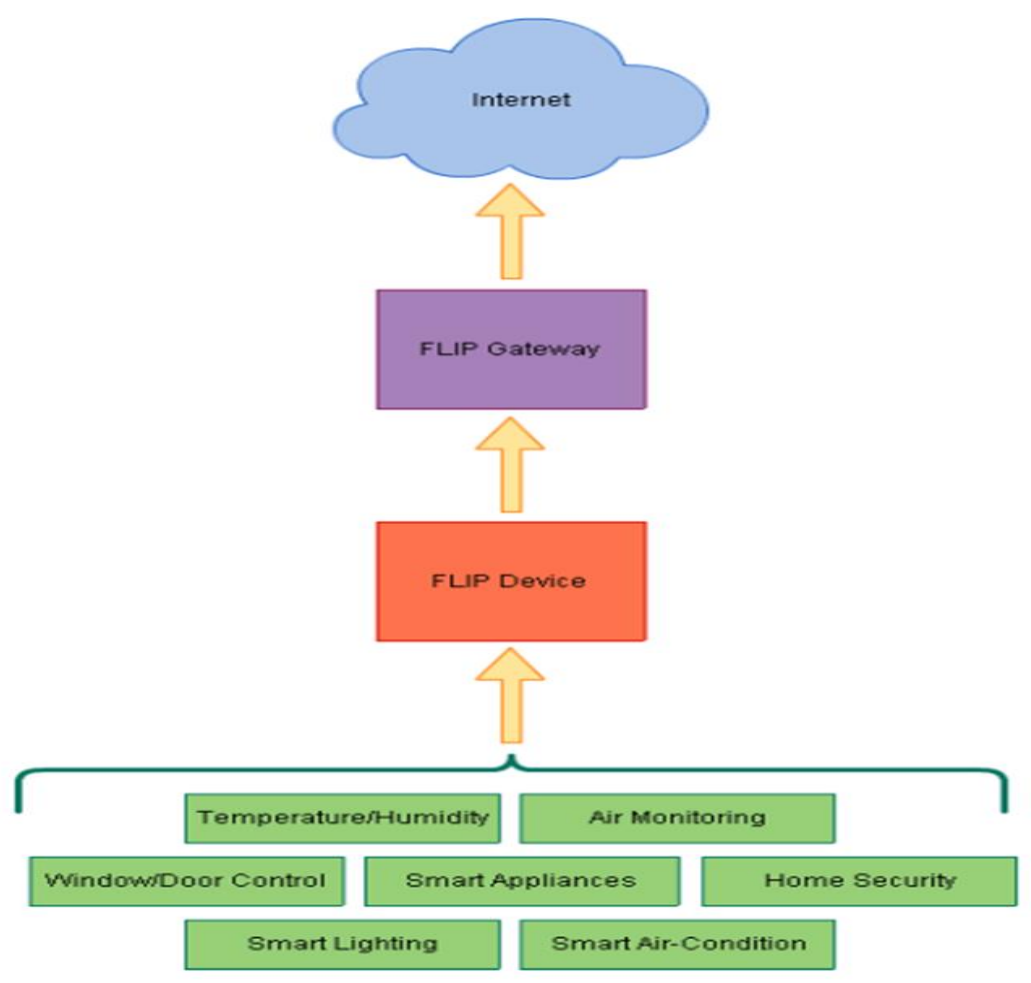

Figure 2. Smart home network structure

(Malche 2017).
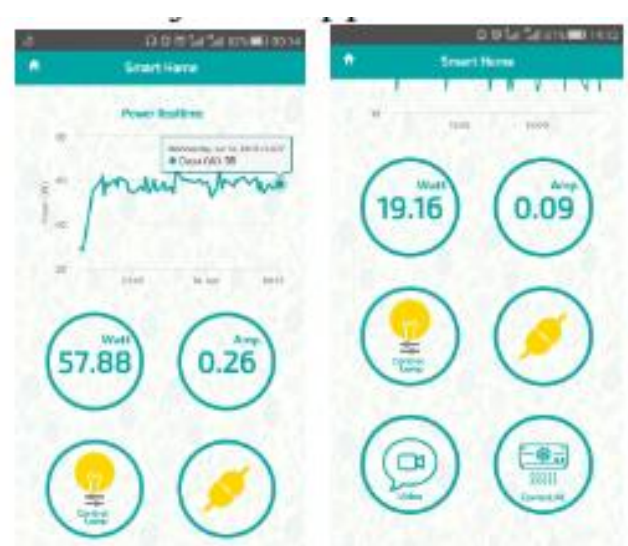

Figure 3. Smart-home-system application (Nurfaif, 2017).

\section{METHOD}

IoT socialization activities are carried out in Bataranila, South Lampung, while IoT skills training is conducted at FTUnila Electronics Laboratory, with the implementation in October 2018. The target audience for the activity was members of the Youth Organization. The number of target audiences as program participants is 20 people. The outline of the evaluation of activities will be carried out in three forms, namely initial evaluation, process evaluation, and final evaluation of activities. The evaluation scheme is presented in Figure 4.

The initial evaluation was carried out at the beginning of the activity, to obtain a general description of the initial conditions of the participants' level of knowledge and understanding. Evaluation of this process is carried out with the aim of knowing and overcoming the problems faced at that stage. The indicator of success in process evaluation is the establishment of a simple IoT system that can be made by the community.

The final evaluation aims to find out how much improvement in knowledge and understanding has been achieved. The achievement indicator is an increase in knowledge and understanding by $30 \%$, and a skill increase of $30 \%$, the analytical method used is the Lickert method. 


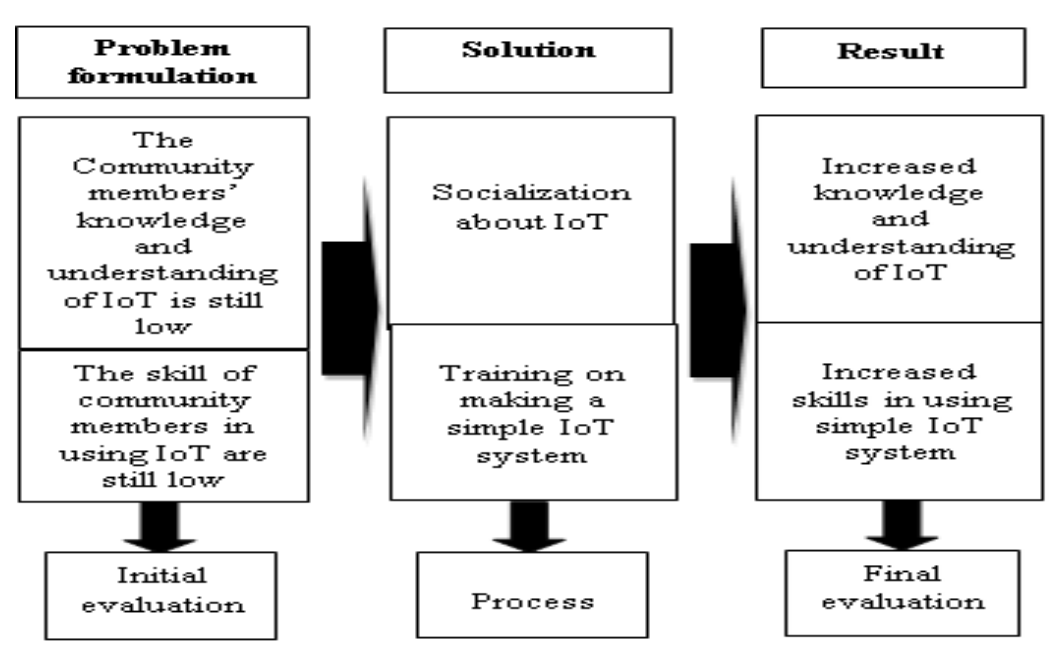

Figure 4. Scheme of Evaluation.

\section{RESULT AND DISCUSSION}

The results of this community service can be seen in Table 1 and Table 2.

Table 1. Pre-Test Results.

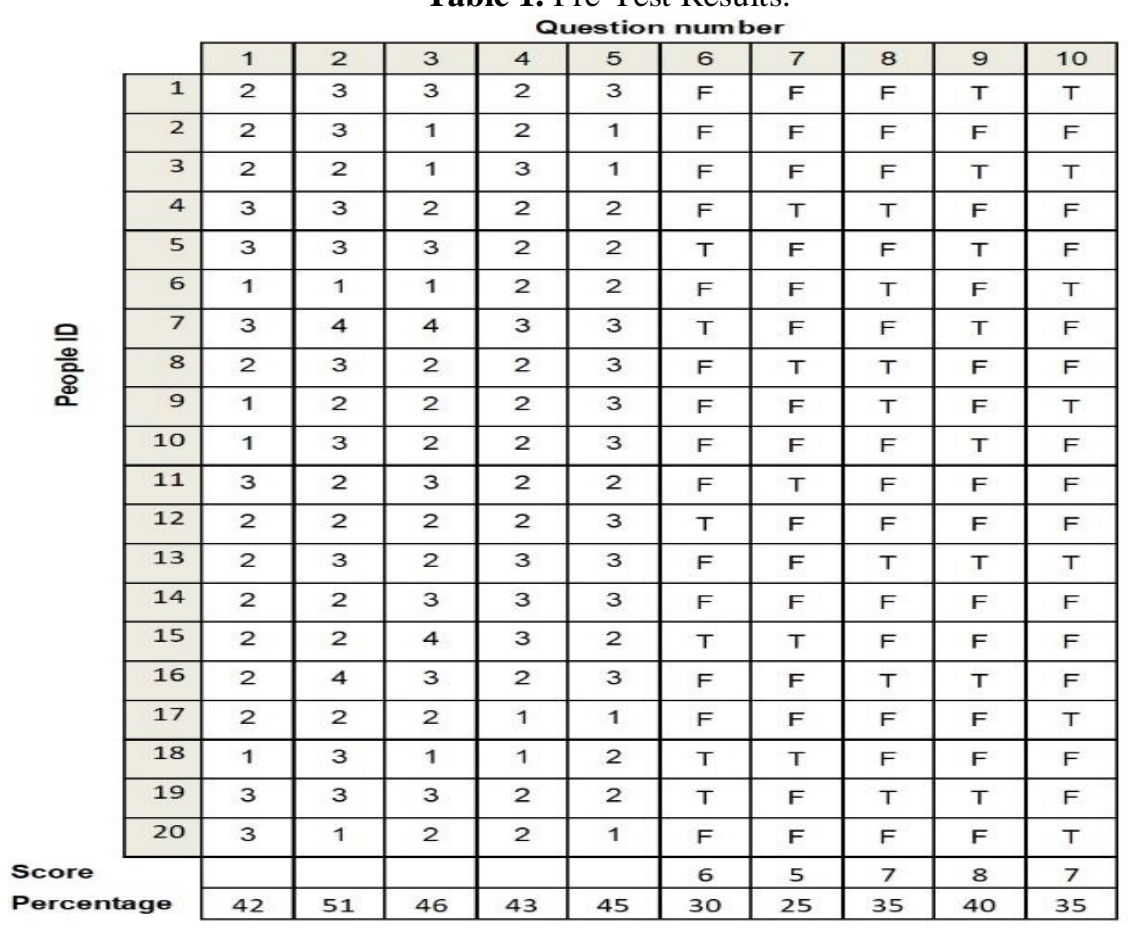


Table 2. Post-test Results.

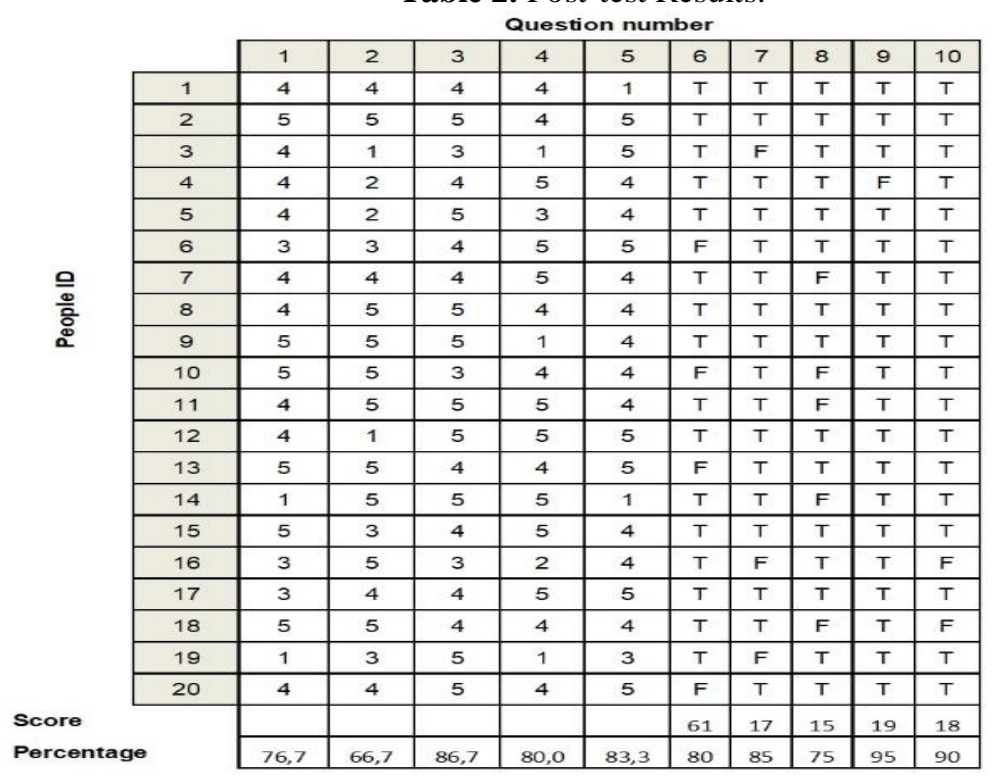

Analysis of the results of community service was carried out using the Likert method. This method is used to measure the perceptions or opinions of a person or group regarding an event based on a predetermined operational definition. Likert method stated in the equation:

$\%$ Index formula $=$ Total Score $/ Y$ x 100

Total score $=\sum_{1}^{n}\left(T \times P_{n}\right)$

Where $\mathrm{Y}$ is the highest Likert $\mathrm{x}$ score with the number of respondents, $\mathrm{T}$ is the total number of respondents and the Likert number option.

From the results of the pre-test and post-test, it can be seen that there is an increase in knowledge about IoT from $45.4 \%$ to $79 \%$ and increased skills from $33 \%$ to $63 \%$. This shows that with the introduction of information and training, it is able to increase public knowledge about the technology of using the Internet for remote control and basic skills regarding electronic circuits supporting IoT.

\section{CONCLUSION}

The results of the pre-test and post-test analysis using the Lickert method showed an increase in knowledge of IoT by $45.4 \%$ to $79 \%$ and an increase in skills by $33 \%$ to $63 \%$. This shows that introducing to people in a village using socialization and training, it is able to increase public knowledge about the technology of using the internet for remote control and basic skills regarding electronic circuits supporting IoT.

\section{ACKNOWLEDGMENTS}

Acknowledgments are addressed to the Directorate of Research and Community Service the Ministry of Research and Higher Education which has provided grant funds through the PPUPIK scheme entitled Digital Village Smart Houses $(R C K D)$ in 2018.

\section{REFERENCES}

Kodali, R.K., V. Jain, S. Bose, L. Boppana. 2016. IoT Based Smart Security and Home Automation System. Proceeding of International Conference on Computing, Communication, and Automation (ICCCA2016). Warangal: National Institute of Technology.

Malche, T., P. Maheshwary. 2017. Internet of Things (IoT) for Building Smart Home System. Proceeding International Conference on I-SMAC, AISECT University. India.

Moroney, L. 2017. The Definitive Guide to Firebase, California, Google.

Nurfaif, M.B., S.R. Sulistiyanti, M. Komarudin, G.F. Nama. 2017. Telemetry and Tele-Control of Electronic Appliance for Smart-Home System. Proceeding of 2017 International Symposium on Electronics and Smart Devices (ISESD). Yogyakarta.

Zhang P., F. Li, and N. Bhatt. 2010. Next-Generation Monitoring, Analysis, and Control for the Future Smart Control Center. IEEE Transactions on Smart Grid Vol. 1 No. 2. Pp: 186-192. 